\title{
Gastric Metastasis of Breast Cancer after 20 Years
}

\author{
Diogo Libânio Mário Dinis-Ribeiro Pedro Pimentel-Nunes \\ Gastroenterology Department, Portuguese Oncology Institute of Porto, Porto, Portugal
}

Keywords

Breast carcinoma - Metastasis - Stomach - Cancer ·

Endoscopy

Metástases Gástricas de Carcinoma da Mama após 20 Anos

\section{Palavras Chave \\ Carcinoma da mama · Metástases · Estômago · Cancro · Endoscopia}

Breast cancer metastases in the gastrointestinal tract are rare $(0.6 \%)$ [1], and when they occur, they are more frequent in the first years after breast cancer diagnosis [2]. We describe a rare case of breast cancer metastasis in the stomach presenting 23 years after breast cancer diagnosis and treatment. The distinction of a primary gastric neo-

\section{KARGER}

E-Mail karger@karger.com www.karger.com/pjg
(C) 2017 Sociedade Portuguesa de Gastrenterologia Published by S. Karger AG, Basel

Karcer

0 pen access

This article is licensed under the Creative Commons AttributionNonCommercial-NoDerivatives 4.0 International License (CC BYNC-ND) (http://www.karger.com/Services/OpenAccessLicense). Usage and distribution for commercial purposes as well as any distribution of modified material requires written permission. plasm and gastric metastasis from another organ may be difficult [3], and the conjugation of clinical history, endoscopic findings, histology, and immunohistochemistry is crucial [4].

Our patient was a 77-year old female with hypertension, dyslipidemia, hypothyroidism, osteopenia, and a history of hysterectomy and bilateral oophorectomy due to uterine fibroids. She had a bilateral lobular breast carcinoma without distant metastasis (M0) in 1993, treated with right quadrantectomy (pT1N0), left radical mastectomy (pT4N1, with lymphatic invasion), bilateral adjuvant radiotherapy, and adjuvant hormonotherapy with tamoxifen during 5 years. There were no signs of local or distant recurrence, and the patient was discharged from our institution 20 years after the diagnosis. In 2016, our patient developed a consumptive syndrome (anorexia and loss of 15\% of her body weight) and vomits, and an upper digestive endoscopy was performed. Hypertrophic gastric folds in the gastric body with an irregular mucosal pattern at narrow-band im- 
Fig. 1. Narrow-band imaging of the hypertrophic gastric folds with an irregular pattern and a $10-\mathrm{mm}$, clean-based ulcer with irregular margins in the incisura. a Hypertrophic gastric folds in the gastric body (white-light endoscopy). b Irregular mucosal pattern (narrow-band imaging). c Clean-based ulcer in the incisura (whitelight endoscopy). d Clean-based ulcer in the incisor (narrow-band imaging).
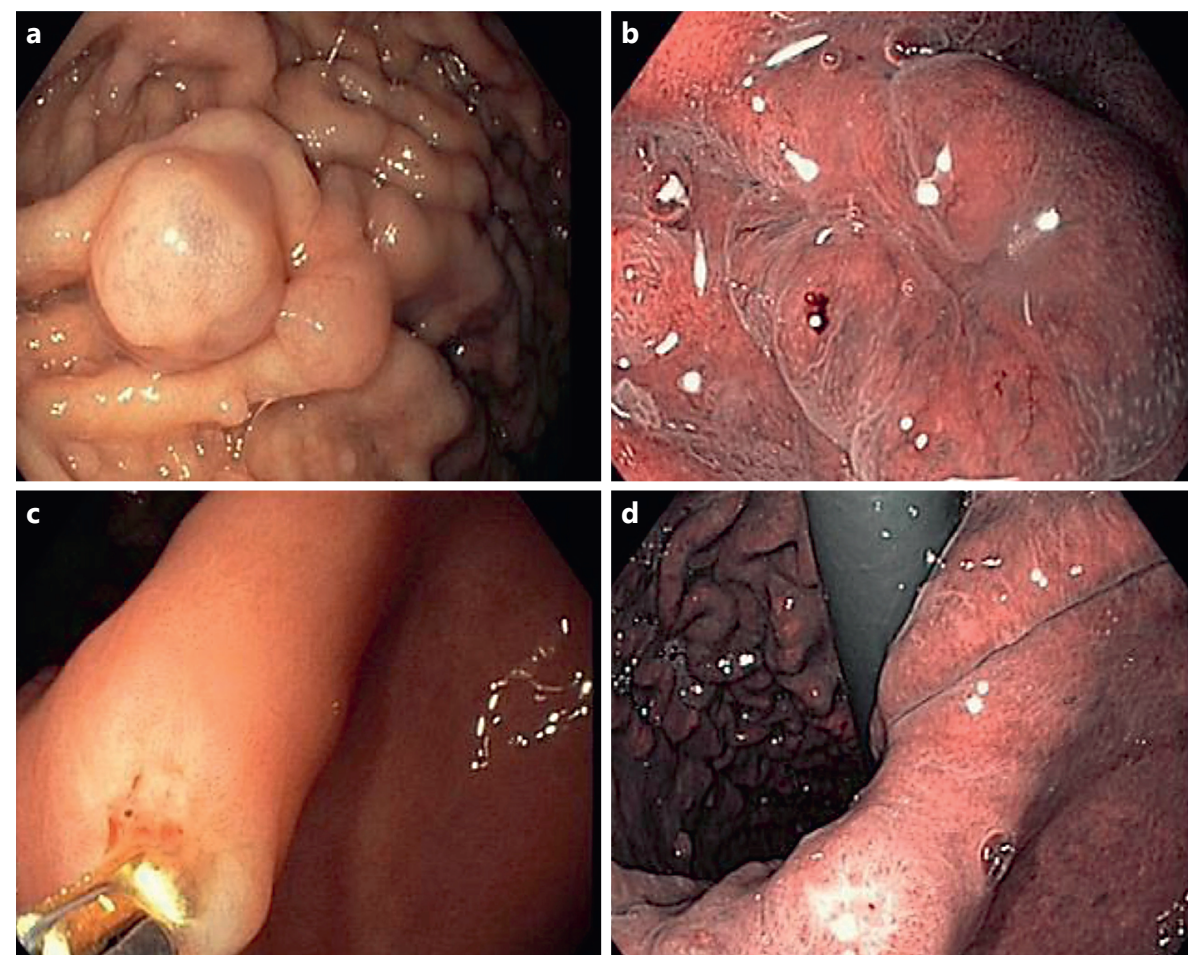

aging observation and an irregular $10-\mathrm{mm}$ ulcer with a clean base at the incisura were found (Fig. 1). Biopsies of the hypertrophic folds and ulcer margins showed infiltration of gastric mucosa by diffuse carcinoma with signet-ring cells (Fig. 2). Due to the history of breast cell carcinoma, immunohistochemistry staining was performed, which was negative for CDX-2 and Her-2 and positive for estrogen receptors (positive in $75-100 \%$ of the neoplastic cells; Fig. 2), allowing the diagnosis of a metachronous gastric metastasis of breast cancer. After the diagnosis, ascites and peritoneal carcinomatosis were detected in computed tomography and positron emission tomography scans, and the patient initiated palliative hormonotherapy with letrozol. After 6 months, the patient is alive and symptomatically ameliorated.

Our case illustrates a very rare case of gastric metastasis from a lobular breast carcinoma treated aggressively many years later. Subtle mucosal gastric alterations should be sought when there is a history of cancer in other organs (particularly lobular breast carcinoma [5]), histology being fundamental to obtain the correct diagnosis. Additionally, immunohistochemistry can aid in the diagnosis when there are doubts about the primary cancer.

\section{Acknowledgements}

We acknowledge Dr. Luís Pedro Afonso and Prof. Rui Henrique for pathological images.

\section{Statement of Ethics}

This study did not require informed consent nor review/approval by the appropriate ethics committee.

\section{Disclosure Statement}

The authors Diogo Libânio, Mário Dinis-Ribeiro, and Pedro Pimentel-Nunes declare that there are no conflicts of interest to disclose.

\section{Author Contribution}

Diogo Libânio, Pedro Pimentel-Nunes, and Mário Dinis-Ribeiro were involved in the conception, writing, and revision of the manuscript. 
Fig. 2. Infiltration of the gastric mucosa with carcinoma and signet-ring cells and immunohistochemistry staining showing positivity for estrogen receptors. $\mathrm{HE}$, hematoxylin and eosin.
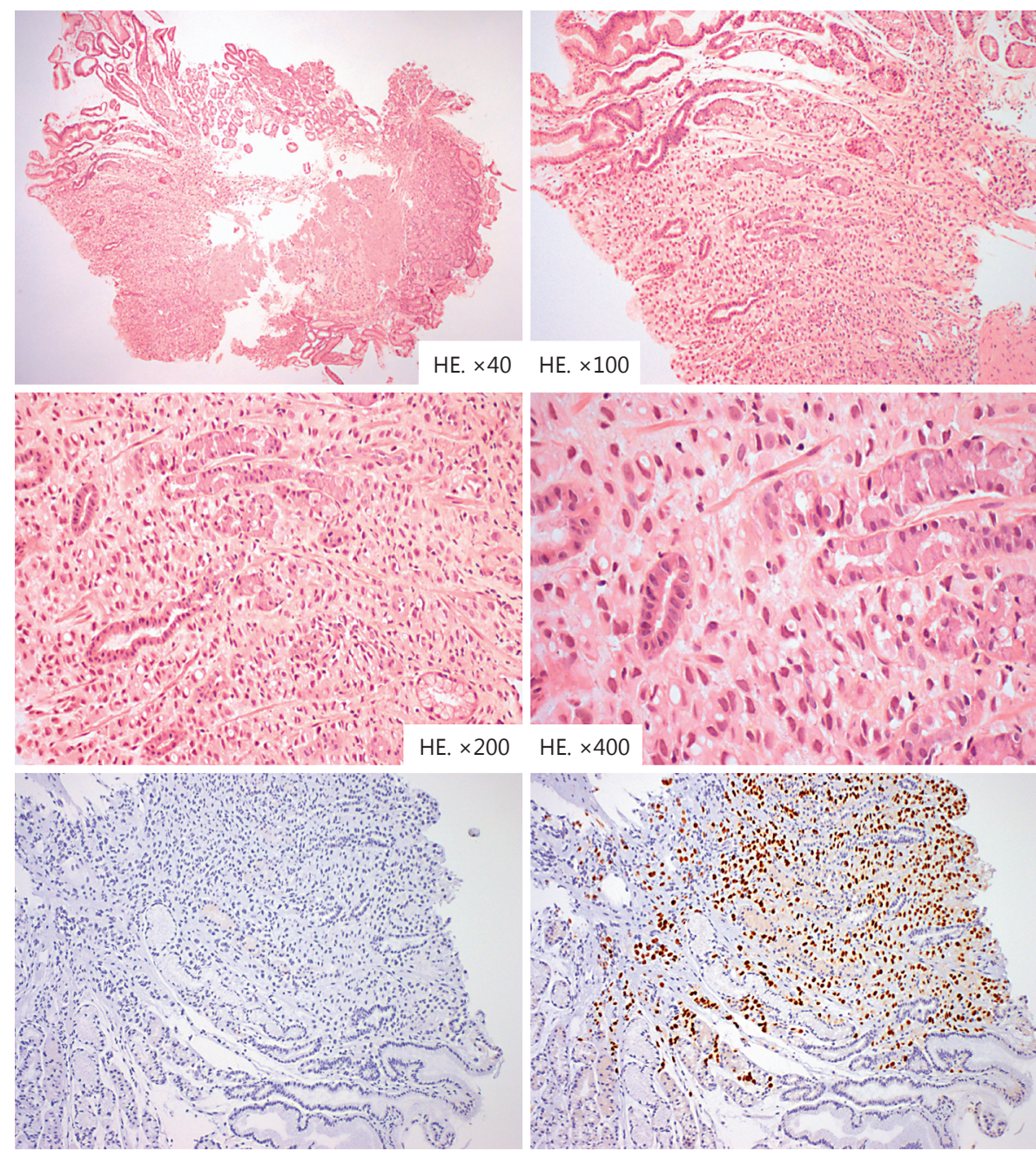

1 McLemore EC, Pockaj BA, Reynolds C, Gray RJ, Hernandez JL, Grant CS, et al: Breast cancer: presentation and intervention in women with gastrointestinal metastasis and carcinomatosis. Ann Surg Oncol 2005;12:886-894.

2 Rodrigues MV, Tercioti-Junior V, Lopes LR, Coelho-Neto Jde S, Andreollo NA: Breast cancer metastasis in the stomach: when the gastrectomy is indicated? Arq Bras Cir Dig 2016;29:86-89.

3 Yagi Y, Sasaki S, Yoshikawa A, Tsukioka Y, Fukushima W, Fujimura T, et al: Metastatic gastric carcinoma from breast cancer mimicking primary linitis plastica: a case report. Oncol Lett 2015;10:3483-3487.

4 Tian Q, Zeng J, Tao X, Zhang Z, Zhou X, Wang Y: Clinical pathology of metastatic gastric carcinoma to the breast: a report of two cases and a review of literature. Oncol Lett 2016;11:3081-3084.

5 El-Hage A, Ruel C, Afif W, Wissanji H, Hogue JC, Desbiens C, et al: Metastatic pattern of invasive lobular carcinoma of the breast - emphasis on gastric metastases. J Surg Oncol 2016;114:543-547. 